\title{
Effect of Trichoderma sp. on Anthracnose Disease of Stored Chilli
}

\author{
ZEE KAR YAN ${ }^{* 1} \&$ VU THANH TU ANH ${ }^{* 1}$ \\ Faculty of Resource Science and Technology, Universiti Malaysia Sarawak, \\ 94300 Kota Samarahan, Sarawak, Malaysia \\ *Corresponding authors: zeekaryan@gmail.com; avthanhtu@unimas.my \\ Received: 21 August 2018 \\ Accepted: 4 December 2018 \\ Published: 30 December 2018
}

Chilli is commonly used as spice in Malaysian culinary, principal ingredients in paste (sambal) and as the raw material in sauce industry. Anthracnose disease caused by Colletotrichum capsici is one of the major causes of economic loss to chilli production especially in Asia. Even a small lesion on chilli might affect the quality, thus the market value of the chilli. Disease symptoms caused by $C$. capsici include brown, circular and sunken lesion with concentric rings of black acervuli. Chemicals have been used to treat the chilli but they might cause environmental pollution, affect human health and lead to pathogen resistance to the chemicals. Therefore, an alternative method to chemical control is required. In this study, C. capsici was isolated from a naturally infected chilli fruit (Capsicum frutescens), and a species of Trichoderma was isolated from the rhizosphere of grasses. Pure cultures of both fungi were established then used in antagonism studies in in vitro and in vivo. Dual culture of pathogens and Trichoderma sp. indicated that Trichoderma sp. competed with $C$. capsici for space and nutrients, caused the loss of turgidity of the fungal hyphae, and reduced the fungal growth by producing volatile metabolites. Trichoderma sp. decreased disease severity on chilli artificially inoculated fruits up to 64\% when Trichoderma mycelial plug was used and 55\% when culture filtrate was applied. Field trials are recommended to examine the antagonism of Trichoderma sp. in real production conditions.

Keywords: Anthracnose, biological control, Colletotrichum capsici, Trichoderma sp.

Copyright: This is an open access article distributed under the terms of the CC-BY-NC-SA (Creative Commons Attribution-NonCommercial-ShareAlike 4.0 International License) which permits unrestricted use, distribution, and reproduction in any medium, for non-commercial purposes, provided the original work of the author(s) is properly cited.

\section{INTRODUCTION}

Capsicum frutescens L. or commonly known as bird eye chilli (Williams et al., 1991) belongs to the family Solanaceae and in the Plantae kingdom. Chilli is one of the most important spice crops in the world (Rahman et al., 2013) and in Malaysia it is used as one of the principal ingredients in paste (sambal) (Karim et al., 2011). Yet, chilli has been attacked by many diseases, and among them, fungal disease is the most important (Rahman et al., 2013).

Anthracnose or commonly known as ripe fruit rot is one of the major causes of economic loss to chilli production (Than et al., 2008a; Than et al., 2008b), especially in Asia (Sangdee et al., 2011). According to Pandey and Pandey (2003), anthracnose caused yield loss of more than $50 \%$ in chilli production in India. Initially, small and circular water-soaked spots will first develop on the skin (Naipagropediaraichur, 2012). The infected surface of the fruit will then sunken and dry up (Than et al., 2008a). Anthracnose is caused by Colletotrichum spp. (Than et al., 2008b). Kim et al. (2014) reported at least five species, which are $C$. gloeosporioides, $C$. acutatum, $C$. coccoides, $C$. dematium and $C$. truncatum were associated with the anthracnose in chilli.

Chemicals have been used to control the anthracnose of chilli (Benítez et al., 2004). However, resistance to the chemicals has been reported for the pathogen of anthracnose (Benítez et al., 2004). In addition, the extensive use of the chemicals might lead to the pollution of the environment and the health of both growers and consumers. In order to reduce the usage of chemicals on the control of chilli anthracnose, alternative control approaches are needed (Rahman et al., 2011).

Antagonists, also known as biological control agents, are mostly soil microorganisms that can interfere with pest's activities (Chernin \& Chet, 2002). There are four mechanisms of antagonists, which are competition, antibiosis, induced resistance and parasitism. Trichoderma spp. are one of the popular fungi known for their antagonism against soil pathogen such as $C$. truncatum which causes anthracnose on chilli 
plants (Chernin \& Chet. 2002; Verma et al., 2007). They are being used widely as biological control agents in many countries (Rahman et al., 2011). Hill et al. (2010) reported that selected Trichoderma isolates helped to enhance the health of Acacia mangium seedlings in Sarawak, Malaysia. Another study by Padder and Sharma (2011) proved that Trichoderma viride had the best potential to inhibit mycelial growth and spore germination of $C$. lindemuthianum.

The objectives of this study were: (1) to study the effect of Trichoderma sp. on the growth of anthracnose pathogen of chilli on culture medium, and (2) to investigate the efficacy of Trichoderma sp. in suppressing development of anthracnose disease on artificially inoculated chilli fruits.

\section{MATERIALS AND METHODS}

Infected fruits of Capsicum frutescens L. with characteristic symptoms of anthracnose for pathogen isolation and healthy fruits for artificial inoculation were purchased locally.

\section{Pathogen Isolation and Pure Culture Establishment}

Naturally infected Capsicum frutescens L. fruits showed the characteristic symptoms of anthracnose including sunken lesion on the fruit skin, which contained numerous black acervuli of conidia masses on the surface of the lesion were used for the isolation (Figure 1). The conidia, when observed under a compound

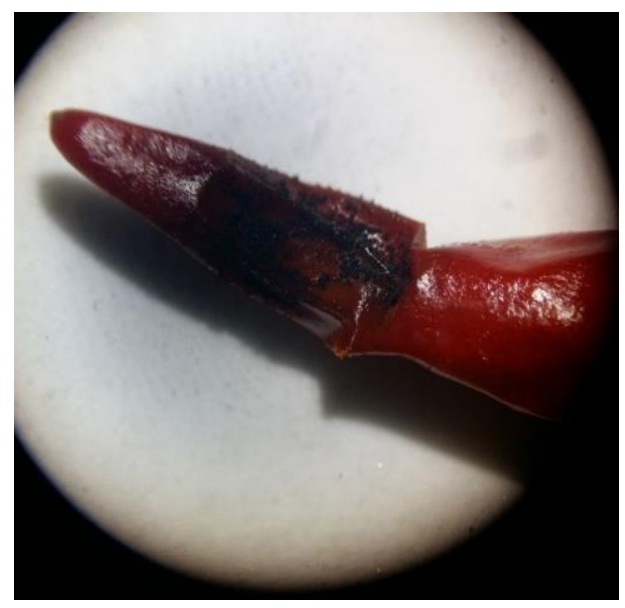

Figure 1. Fruits of bird eye chillies with characteristic symptoms of anthracnose. microscope at $400 \times$ magnification, appeared to be tapering towards each end with acute apex and truncate base.

Potato Dextrose Agar (PDA) was used for the isolation of associated pathogen, which followed the method described by Ratanacherdchai et al. (2010). The infected fruits were first surface sterilised with $5 \%$ of Clorox ${ }^{\circledR}$ bleach (10\% sodium hypochlorite) for two minutes and rinsed three times with sterile distilled water. Three sterilised specimens excised from the borderline of infected and healthy area were then placed onto each of five PDA replicate plates, and the plates were incubated for four to seven days at room temperature (approximately $28{ }^{\circ} \mathrm{C}$ ). Pure culture of the pathogen was obtained using single spore isolation method (Choi et al., 1999). Briefly, a loopful of spore mass of 7-day old culture was transferred into a centrifuge tube which contained $10 \mathrm{ml}$ of sterile distilled water, and the solution was gently shaken to disperse the spore mass. The solution was then poured onto PDA plates and left to stand for 5 minutes. The excessive solution on the plates was then poured off, and the plates were incubated slanting for 12 to 18 hours. Single spores of Colletotrichum capsici that germinated between 18 to 24 hours were transferred onto new PDA plates. The isolated C. capsici was identified based on the descriptions by Liu et al. (2016), based on the macro- and microscopic structures of the fungus.

\section{Pathogenicity Test}

Before surface sterilization, healthy fruits of Capsicum frutescens L. were washed with running tap water for half an hour to remove any contaminants on the surface of the fruits. The fruits were then surface sterilised with $70 \%$ ethanol for five minutes based on the method described by Sangdee et al. (2011). The sterilised fruits were then washed with sterile distilled water and left to dry on a sterilised filter paper in a laminar flow. Two wounds per fruit were created on sterilised chilli fruits using sterilised scalpel, and a plug of a 7-day old pure culture of the fungus was transferred and inserted into the wounds. Chilli fruits which served as controls had PDA plugs inserted into the wounds. The inoculated fruits were then 
placed in transparent plastic boxes. There were five replicates boxes (five fruits per box) for each treatment and the boxes were kept at room temperature and observed daily. Symptoms at the inoculation site were evaluated one week after the inoculation (Montri et al., 2009) and compared with the symptoms observed from the naturally infected fruits. Re-isolation of the fungus from the artificially inoculated fruits was carried out for comparison with the fungus isolated from the naturally infected fruits. The infected tissues were taken from about $1 \mathrm{~cm}$ from the point of inoculation and underwent surface sterilization before being transferred onto new PDA plates. The plates were then incubated at room temperature, and the colonies were observed for the spore and colony characteristics.

\section{Isolation of Antagonistic Fungus}

Trichoderma sp. was isolated from rhizosphere soil of grasses following the method described by Bharathi et al. (2004). Rhizosphere soil samples were collected and diluted in test tubes up to $10^{-6}$. Pure culture of Trichoderma sp. was established using single spore isolation (Choi $\mathrm{et}$ al., 1999), as described earlier for the establishment of Colletotrichum pure culture. Identification of the isolated Trichoderma sp. was based on the description by Shah et al. (2012) by observing the macro- and microscopic structures of the fungus. The pure culture of Trichoderma sp. was subsequently used in antagonism test in culture plate with Colletotrichum sp. and on artificially inoculated chilli fruits.

\section{Antagonistic Activity of the Trichoderma sp. on Culture Plate}

Isolated Trichoderma sp. was screened for its antagonistic activity against Colletotrichum sp. using dual culture technique described by Begum et al. (2008). Briefly, an agar disc containing mycelia of 7-day-old Trichoderma sp. culture was placed at one end of the agar plate while an agar disc containing mycelia of 7-day-old Colletotrichum sp. culture was placed at the other end on the same PDA plate (hereinafter referred to as Treated plate). Plates, which served as controls, had agar disc of Colletotrichum sp. mycelia and a disc of PDA placing opposite each other on PDA plates.
There were five replicate plates for each treatment, and the plates were incubated for 15 days at room temperature. The plates were observed daily, and the average growth rate of Colletotrichum sp. and Trichoderma sp. was computed using the formula described by Rosli (2017) (Eq. 1) and the antagonistic activity of the Trichoderma sp. toward Colletotrichum sp., expressed as percentage of inhibition of radial growth was determined using the formula described by Begum et al. (2008) (Eq. 2) as below.

Average growth rate:

$\underline{(\mathrm{D} 2-\mathrm{D} 1)+(\mathrm{D} 3-\mathrm{D} 2)+(\mathrm{D} 4-\mathrm{D} 3)+[\mathrm{DN}-\mathrm{D}(\mathrm{N}-1)] \quad \text { Eq. (1) }}$ $\mathrm{N}-1$

Where $\mathrm{D}$ indicates the average colony radial of Colletotrichum sp. and $\mathrm{N}$ indicates the number of days after incubation.

Percent inhibition of radial growth:

$$
\underline{\mathrm{R} 1-\mathrm{R} 2} \quad \mathrm{x} 100
$$

$\mathrm{R} 1$

Where R1 indicates the radial growth of the fungal colony of the control set, and R2 indicates the radial growth of the fungal colony of the treated set.

Scanning Electron Microscopy (SEM) was used to observe the interaction between the two fungi after the Trichoderma sp. had grown over the Colletotrichum sp. on the dual culture plates. Agar plugs from confrontation zone were fixed in phosphate buffer solution $(\mathrm{pH} 7)$ for 24 hours as described by Carvalho et al. (2014). Phosphate buffer solution was prepared by combining the stock solution of $1 \mathrm{M}$ of dipotassium phosphate $\left(\mathrm{K}_{2} \mathrm{HPO}_{4}\right)$ and $1 \mathrm{M}$ of monopotassium phosphate $\left(\mathrm{KH}_{2} \mathrm{PO}_{4}\right)$ to 11 of distilled water. After 24 hours, the samples were rinsed with fresh buffer solution for three times, and the solution was replaced by the lowest concentration of ethanol solution and left for one hour for dehydration purpose. The ethanol concentrations used were $60 \%, 80 \%$ and $100 \%$. Lastly, the samples were placed in $100 \%$ ethanol overnight. The samples were then dried with carbon dioxide in a critical point dryer, mounted on aluminium stubs with double-sided tape and coated by gold. The samples were visualized by using a SEM (JEOL, JSM639OLA). 


\section{Action of Volatile Metabolites of Trichoderma sp. on Colletotrichum sp.}

For volatile metabolites test, technique described by Muthukumar et al. (2011) was used with modification by sealing the plates together with parafilm. Briefly, agar disc containing mycelia of 7-day-old Trichoderma sp. culture and Colletotrichum sp. culture were placed separately at the centre of the bottom of each PDA plate, respectively. Next, the lids of the PDA plates which contained Trichoderma sp. agar disc were replaced by the bottom of PDA plates which contained Colletotrichum sp. agar disk. The two plates were sealed together with parafilm (hereinafter referred to as Treated plate). Plates served as the controls were prepared in the same manner, except that PDA discs were used instead of Trichoderma sp. mycelial discs (hereinafter referred to as Control plate). There were five replicate plates for each treatment, and the plates were incubated at room temperature until the mycelia of Trichoderma sp. was observed to start growing over the other plate containing Colletotrichum sp.. The plates were observed daily, and percentage of inhibition of radial growth of the pathogen was determined. Formula described by Rosli (2017) was used to record the growth of Colletotrichum sp. and Trichoderma sp.. Formula described by Begum et al. (2008) was used to analyse the antagonistic activity of Trichoderma sp.

\section{Inhibitory Efficacy of Trichoderma sp. against Anthracnose Pathogen Growth and Disease Development on Chilli Fruits}

Healthy fruits were first inoculated artificially with Colletotrichum sp. then treated with Trichoderma sp. based on method described by Kim et al. (2014) with modification by creating the wounds using sterilised scalpel. Briefly, healthy fruits were surface sterilised with $70 \%$ ethanol for five minutes. The sterilised fruits were then washed with sterile distilled water and left to air dry on a sterilised filter paper in a laminar flow. A plug of 7-day old Colletotrichum sp. culture was transferred and inserted into a sterilised fruit after the wound was created on the surface of the fruit using a sterilised scalpel. A second wound was made approximately $1 \mathrm{~cm}$ apart from the initial wound, and a plug of 7-day old Trichoderma sp. culture was transferred and inserted into the wound. Chilli fruits, which had Colletotrichum sp. culture and a PDA plug inserted into the first and second wound, respectively, served as the controls. Treated chilli fruits were placed separately in plastic containers, three chilli fruits per container, for each treatment, and the containers were arranged in a Completely Randomised Design. There were five replicate containers for each treatment, and the containers were incubated for 15 days at room temperature. Disease incidence and severity were recorded and computed using Eq (3) and Eq. (4).

Percent of fruit rot incidence $=$

$$
\frac{\text { No. of fruit rot }}{\text { Total no. of fruit }}
$$

(Ngullie et al., 2010)

Percent of disease severity $=$

$$
\frac{(\mathrm{R}-\mathrm{C})}{\mathrm{R}} \times 100 \times 100
$$

(Rahman et al., 2011)

Where $\mathrm{R}$ indicates the average of lesion radius on chilli fruit in the presence of the antagonist and $\mathrm{C}$ indicates the average of lesion radius on chilli fruits without the antagonist (control).

\section{Culture Filtrate Study}

Six plugs of Trichoderma sp. mycelia were grown in each Schott bottle containing $250 \mathrm{~mL}$ sterile potato dextrose broth (PDB), four replicate bottles, on a shaker at $100 \mathrm{rpm}$ for 15 days at room temperature based on method described by Rahman et al. (2012). The culture broth was filtered twice, first through a layer of sterilised filter paper (Whatman No. 1) and then a sterilised membrane filter (Whatman, 0.22 $\mu \mathrm{m})$. Healthy fruits of bird eye chilli were surface sterilised with $70 \%$ ethanol for five minutes. The sterilised fruits were then washed with sterile distilled water and left to air dry on a sterilised filter paper in a laminar flow. Surface sterilised chilli fruits were then dipped in $100 \mathrm{ml}$ of culture filtrate of Trichoderma sp. for 24 hours. Chilli fruits which served as controls were dipped in $100 \mathrm{~mL}$ of sterile distilled water. After 24 hours, the dipped chilli fruits were left to air dry on a sterilised filter paper in a laminar flow. A plug of Colletotrichum sp. culture was transferred and inserted into a wound created on each dipped 
fruit using a sterilised scalpel based on method described by Nantawanit et al. (2010). Chilli fruits, which served as the controls, had only PDA plug inserted into the wounds. The treated chilli fruits were placed in plastic containers for each treatment, and the containers were arranged in a Completely Randomised Design. There were five replicate containers with three chilli fruits in each container, and the containers were incubated for 15 days at room temperature. Disease incidence and severity were recorded and computed using the formulae described by Ngullie et al. (2010) and Rahman et al. (2011), respectively.

\section{Statistical Analysis}

All the data were first subjected to a test for Normality. The data were then subjected to Analysis of Variance (ANOVA) if the data were normally distributed or non-parametric test (Wilcoxon signed-rank test and MannWhitney U test) if the data were not normally distributed. Tukey test as post-hoc test for ANOVA was used to compare the means between treatments. All statistical analysis was performed using the software SPSS version 24.

\section{RESULTS}

\section{Pathogen Isolation and Pure Culture Establishment}

Isolation of the causal agent on PDA resulted in two types of colonies. However, a dark grey colour colony with cottony mycelium and concentric rings from the middle of the colony was the most predominant on the culture plate, and therefore was selected to be subcultured for further studies. A pure culture of the predominant fungus had been successfully established, which was then used for pathogenicity test on chilli fruits and preliminary identification.

Figure 2 shows the colony morphology of the pure culture of the microorganism isolated from the naturally infected chilli fruit. As can be seen from the Figure, both upper and reverse view of the colony have dark grey colour with cottony mycelium and concentric rings from the middle of the culture plate. Microscopic observation of the isolated fungus showed setae, which had smooth-walled, tapered to paler acute apex and slightly swollen at the base and brown in colour (Figure 3A). Hyphae of the isolated fungus were septate and conidia appeared to be a quarter moon shape, tapering towards each end with acute apex and truncate base (Figure 3B).

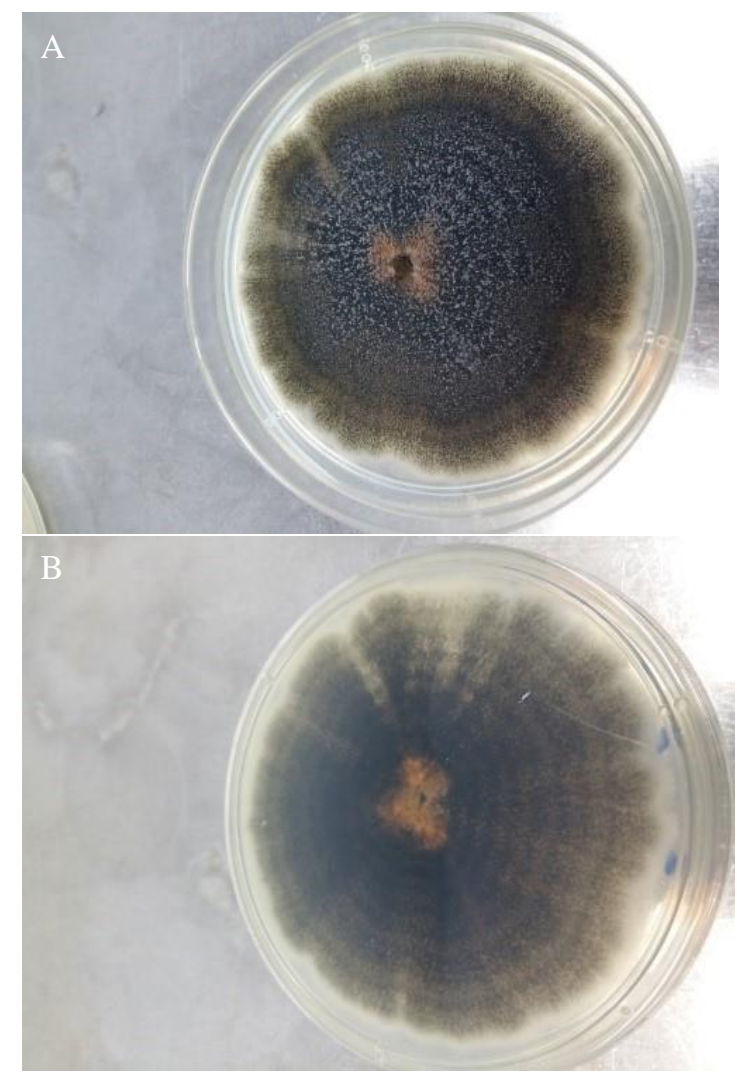

Figure 2. Colony morphology of the pure culture of the isolated fungus on PDA. (A) Upper view, (B) Reserve view.

\section{Pathogenicity Test}

All healthy chilli fruits, which were artificially inoculated with the pure culture of the isolated fungus, showed signs of white mycelial growth on the surface of the inoculated chilli fruits from second days after inoculation. Figure 4 shows disease symptoms developed on artificially inoculated and non-inoculated (controls) chilli fruits, respectively, at seven days of incubation. As can be seen from Figure 4, the chilli fruits, which were inoculated with plugs of fresh potato dextrose agar (controls), remained unaffected. However, the wounds on the artificially inoculated chilli fruits, where the mycelial discs were inserted, became black in colour. There were sunken lesions developed and black acervuli were observed on the surface 

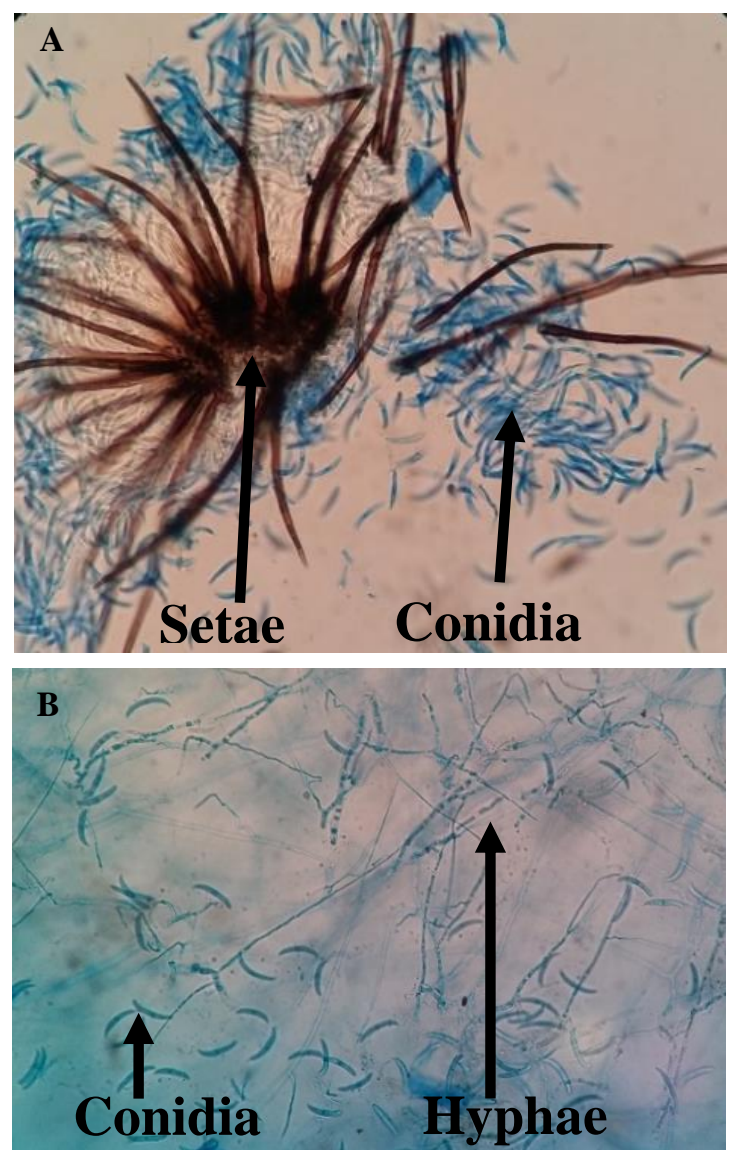

Figure 3. Microscopic structures of C.capsici under 400x magnification. (A) Setae and conidia, (B) Hyphae and conidia

of the lesion. These symptoms were similar to those observed from the naturally infected chilli fruits, from which the pathogen was isolated. Re-isolation of the fungus from an area between infected and healthy tissue gave rise to a colony with pale grey in colour and cottony mycelium from the middle of the culture plate from the upper view.

On the reverse view, the colony was dark brown colour with concentric rings from the middle of the culture plate. Microscopic structures of the fungus (hyphae and conidia) were similar to those that were isolated from the naturally infected chilli fruits except that the hyphae were much smaller in size. The characteristics of the isolated fungus resembled to those described for Colletotrichum capsici, causing anthracnose disease of chilli fruits (Saxena et al., 2016; Shenoy et al., 2007). The fungus, therefore, was preliminarily identified as a Colletotrichum capsici, and was confirmed to be the causal agent of the disease.
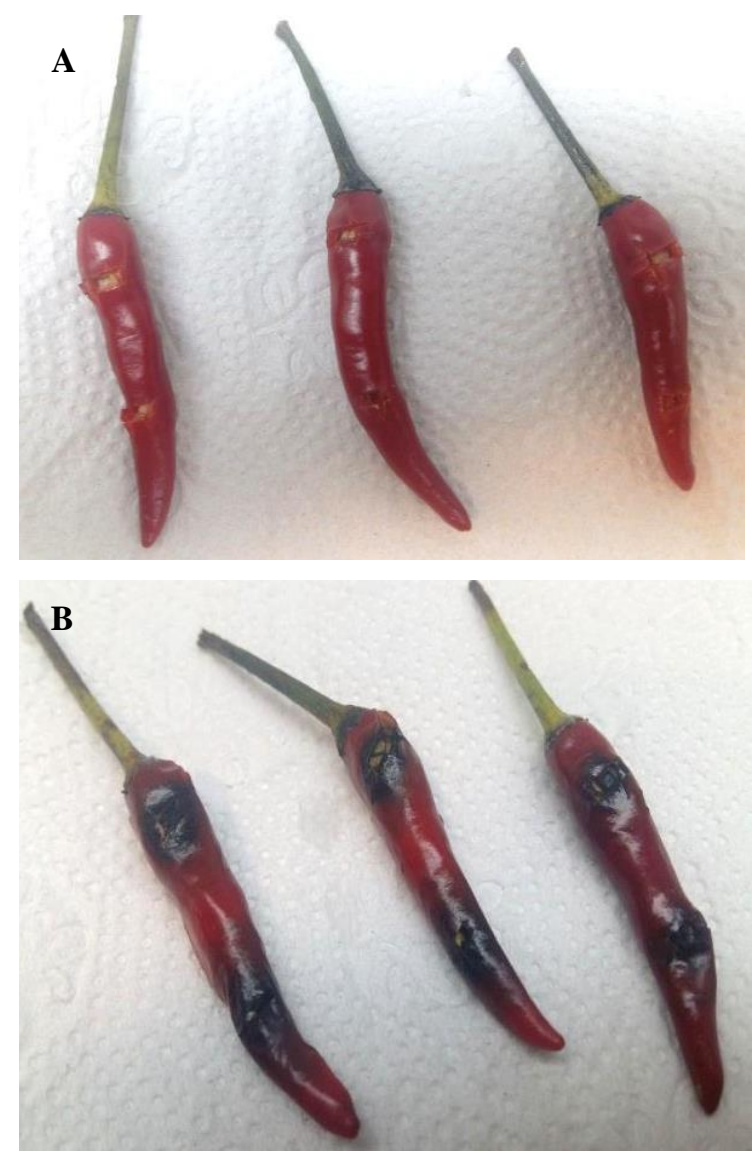

Figure 4. Chilli fruits inoculated with PDA plugs (A; controls) and with mycelial plugs of the isolated fungus $(\mathrm{B})$ on the $7^{\text {th }}$ day of inoculation.

\section{Isolation and Morphology Characteristics of Antagonistic Fungus}

A Trichoderma sp. was successfully isolated from rhizosphere soil near the root surface of grasses. Pure culture of the isolated fungus showed characteristics of Trichoderma sp. based on the description by Shah et al. (2012). Colour from upper surface varied from whitish (Figure 5A1) to greenish (Figure 5A2) and lower surface appeared whitish (Figure 5B1) to yellowish. The conidiophore of the isolated species appeared as branches, and its conidia were round in shape (Figure 6).

\section{Antagonistic Activity of the Trichoderma sp. on Culture Plate}

Dual culture technique was performed to screen for antagonistic activity of Trichoderma sp. against Colletotrichum capsici. Trichoderma sp. grew faster as compared to $C$. capsici. Besides, the colour of C. capsici colony 

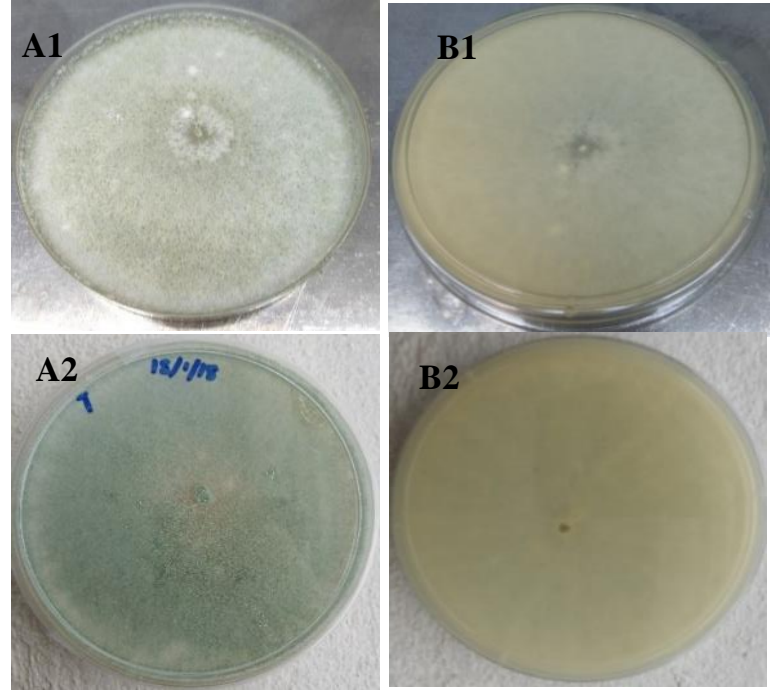

B2

Figure 5. Colony morphology of Trichoderma sp. on PDA $(\mathrm{A} 1,2)$ Upper view, $(\mathrm{B} 1,2)$ Reserve view.

observed in the control plates was lighter in colour as compared to that in the treated plates (Figure 7). On the third day of inoculation, Trichoderma sp. started to overgrow the colony of $C$. capsici. Results from the test showed that the average growth rate of $C$. capsici was significantly $(\mathrm{p}<0.05)$ slowed down by Trichoderma sp.. The average growth rate of $C$. capsici on the control plates and the treated plates was $0.94 \mathrm{~cm}$ and $0.85 \mathrm{~cm}$, respectively.

Figure 6. Microscopic structure of Trichoderma sp.

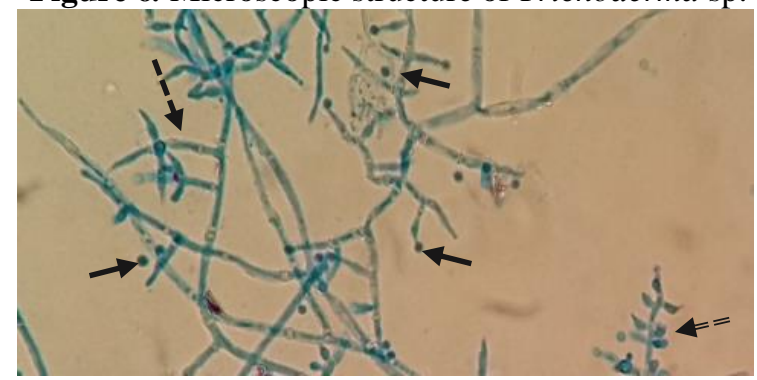

under 400x magnification. Conidiophore (black dashed arrow) and conidia (black arrow).
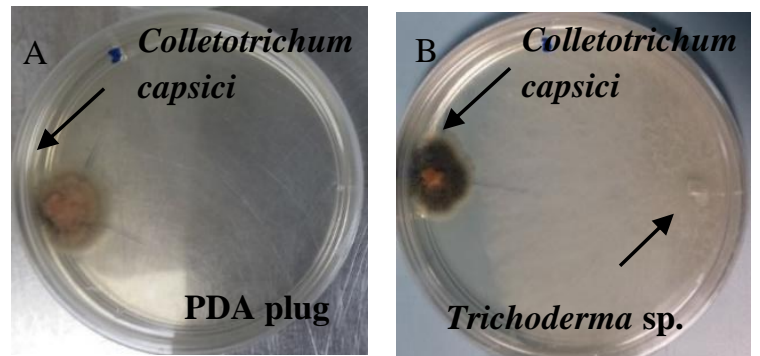

Figure 7. Colour of Colletotrichum capsici colony in dual culture plate on second day of incubation.
(A) Control plate, (B) Treated plate.

The highest percent inhibition of radial growth of $C$. capsici recorded was on the third day of incubation $(30.87 \%$ ) followed by $26.83 \%$ on the first day, $18.81 \%$ on the second day and $14.80 \%$ on the fourth day. In all plates, Trichoderma sp. completely overgrew the colony of $C$. capsici in fourth day of incubation (Figure 8).

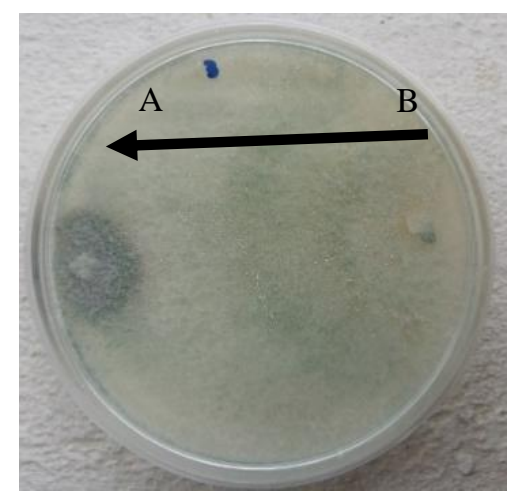

Figure 8. Growth of Trichoderma sp. over Colletotrichum capsici on a dual culture plate on $14^{\text {th }}$ day of incubation. (A) Colletotrichum capsici colony, (B) Trichoderma sp. colony.

Morphology of the hyphae of $C$. capsici at the confrontation zone showed a deformed shape when observed under SEM (Figure 9). The hyphae of $C$. capsici were less turgid and seemed lysed by Trichoderma sp. (Figure 9b).
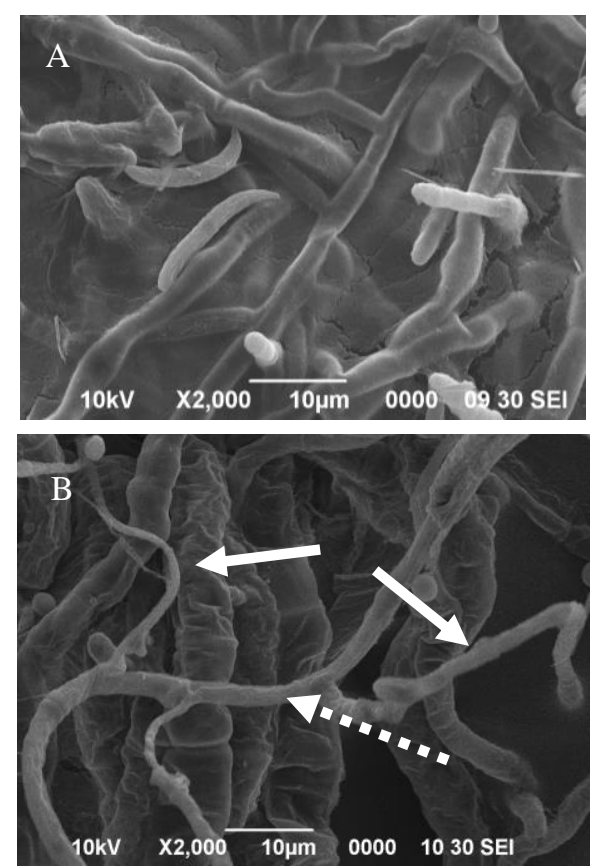

Figure 9. Change in hyphal morphology of Colletotrichum capsici (white arrow) when in contact with hyphae of Trichoderma sp. (dashed arrow) 14 days after incubation (B) under SEM with 2000x magnification as compared with control set (A). 


\section{Action of Volatile Metabolites of Trichoderma sp. on Colletotrichum capsica}

Trichoderma sp. grew faster as compared to Colletotrichum capsici. The colour of the $C$. capsici colony observed in the Control plates was lighter as compared to that in the Treated plates (Figure 10). Besides, the growth of the colony in the Control plates was more even as that compared to the Treated plate. On the sixth day of incubation, Trichoderma sp. started to grow over toward the colony of $C$. capsici plated on top of the Trichoderma sp. plate. The result of the volatile metabolites effect of Trichoderma sp. showed that Trichoderma sp. did not significantly $(\mathrm{Z}(6)=1.59, \mathrm{p}=0.26)$ inhibited radial growth of $C$. capsici after seven days of inoculation on PDA medium. However, growth rate of $C$. capsici in the Control plates and the Treated plates was significantly different $(\mathrm{p}<0.05)$. The average growth rate of C. capsici in the Control and Treated plates was $1.08 \mathrm{~cm}$ and $0.93 \mathrm{~cm}$, respectively. In all plates, Trichoderma sp. completely grew over onto the plate containing the colony of $C$. capsici in $14^{\text {th }}$ days of incubation.

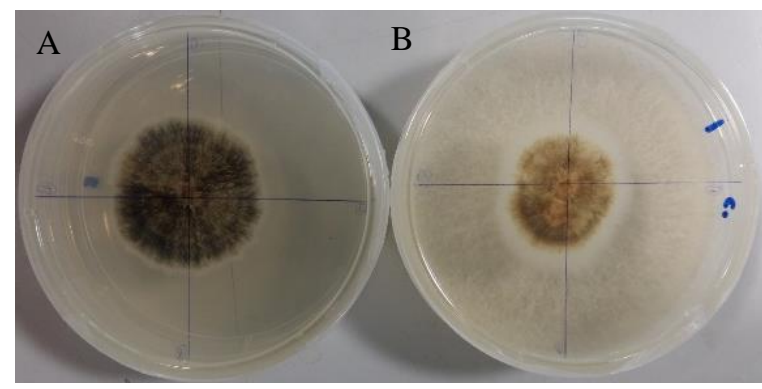

(A) Control plate, (B) Treated plate.

Figure 10. Colour of Colletotrichum capsici colony in volatile test on fourth day of incubation.

Table 1: Effect of Trichoderma sp. volatile metabolites on radial growth of Colletotrichum capsica.

\begin{tabular}{cc}
\hline Day & $\begin{array}{c}\text { Percent inhibition of mean } \\
\text { radial growth }(\%)\end{array}$ \\
\hline 1 & $8.33 \pm 6.134$ \\
2 & $25.95 \pm 3.983$ \\
3 & $20.72 \pm 4.467$ \\
4 & $17.50 \pm 3.340$ \\
5 & $17.01 \pm 3.086$ \\
6 & $11.57 \pm 1.765$ \\
7 & $13.02 \pm 4.091$ \\
\hline standard deviation
\end{tabular}

\pm standard deviation

\section{Inhibitory Efficacy of Trichoderma against Anthracnose Pathogen Growth and Disease Development on Chilli Fruits}

The results showed that Trichoderma sp. significantly $(\mathrm{p}<0.05)$ inhibited growth and development of Colletotrichum capsica (Table $2)$. All the fruits, artificially inoculated with plugs of $C$. capsici regardless of presence of Trichoderma sp., showed symptoms of anthracnose. The disease incidence was therefore $100 \%$. The symptoms observed on the fruits in this experiment were the same as those observed in the pathogenicity test (Figure 11). However, mycelia of Trichoderma sp. were observed to cover all over the wounded chilli fruits (Figure 11B).
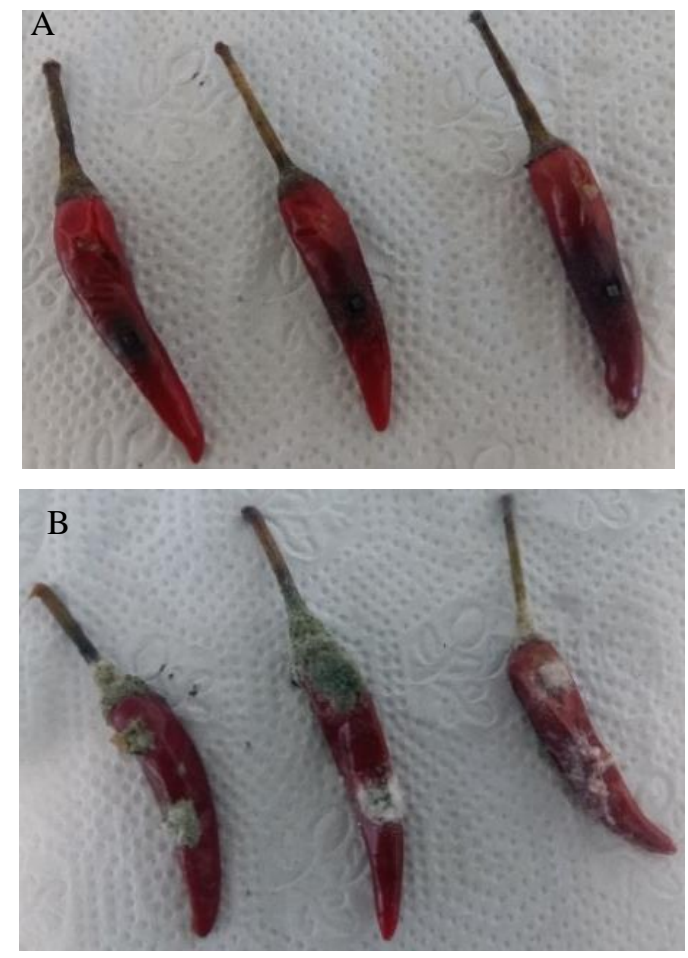

Figure 11. Diseases symptoms on chilli fruits artificially inoculated with Colletotrichum capsici (A) treated with PDA plugs and (B) treated with Trichoderma sp. plugs on fifth day after inoculation.

Table 2: Effect of Trichoderma sp. on disease severity caused by Colletotrichum capsica.

\begin{tabular}{cc}
\hline Day & Percent of disease severity (\%) \\
\hline 2 & $14.11 \pm 7.926$ \\
3 & $19.21 \pm 6.036$ \\
4 & $64.35 \pm 22.082$ \\
5 & $50.09 \pm 19.527$ \\
\hline I standard deviation
\end{tabular}




\section{Culture Filtrate Study}

The results indicated that the culture filtrates of Trichoderma sp. significantly inhibited the growth of Colletotrichum capsici and the development of anthracnose disease on the artificially inoculated chilli fruits (Table 3). There was $100 \%$ of disease incidence, and the symptoms that were developed on the fruits in this experiment were the same as those observed in the pathogenicity test (Figure 12).

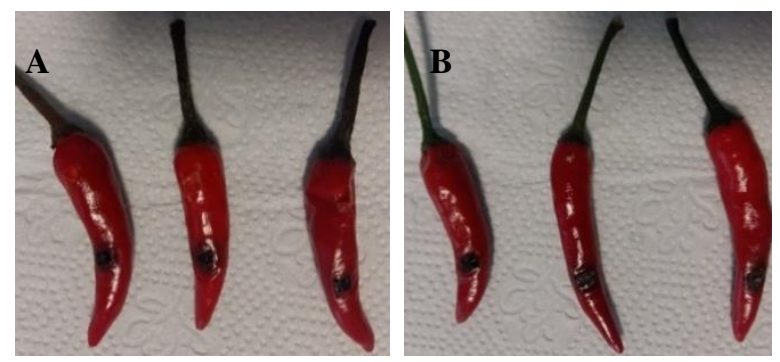

Figure 12. Culture filtrate of Trichoderma sp. on wounded chilli fruits with Colletotrichum capsici. (A) Control treatment, (B) Treated treatment.

\section{DISCUSSION}

Anthracnose is one of the major causes of economic loss to chilli production (Than et al., 2008a; Than et al., 2008b). Chemicals have been used to control the anthracnose of chilli but resistance has been developed in the pathogen of anthracnose (Benítez et al., 2004). In order to reduce the usage of the chemicals on the control of chilli anthracnose pathogen, alternative control approaches are needed (Rahman et al., 2011). Antagonists, soil microorganisms that can interfere with pest's activities such as Trichoderma spp. are one of the popular fungi known for their antagonism (Chernin \& Chet, 2002; Verma et al., 2007).

The pathogen associated with the naturally infected chilli was successfully isolated out and proved to be pathogenic. The pathogen was preliminarily identified as Colletotrichum capsici since it had similar characteristics of dark grey colony to that described for $C$. capsici by Liu et al. (2016), of septate hyphae, the quarter moon shape of the conidia, and the presence of setae as those described for $C$. capsici by Shenoy et al. (2007). However, it is worthwhile to have a molecular analysis to confirm the species.
Table 3: Effect of Trichoderma sp. culture filtrate on disease severity caused by Colletotrichum capsici

\begin{tabular}{cc}
\hline Day & Percent of disease severity $(\%)$ \\
\hline 2 & $18.51 \pm 4.383$ \\
3 & $37.14 \pm 5.389$ \\
4 & $31.70 \pm 11.612$ \\
5 & $55.00 \pm 13.845$ \\
\hline
\end{tabular}

The antagonist that successfully isolated out was identified as a Trichoderma sp.. The green colony characteristics observed in the present study were in agreement with those described in the studies by Shah et al. (2012). The branching conidiophore and round and green colour conidia of the isolated Trichoderma sp. in the present study were similar to those described in the study by Armando et al. (2017).

In the present study, Trichoderma sp. reduced the mycelia growth of Colletotrichum capsici in dual culture assay. The mechanism observed in the dual culture assay by Trichoderma sp. might be the competition for space and nutrients between the pathogen and the antagonist (Amin at al., 2010b) and lysis (Begum et al., 2008). Growth of Trichoderma sp. over $C$. capsici was also observed in the study by Amin et al. (2010a) and Sawant (2014). In addition, Intana et al. (2007), when examined the efficacy of three mutant and two wild type strain of $T$. harzianum in inhibiting mycelia growth of $C$. capsici, also reported that all the strains of Trichoderma were able to inhibit and overgrow the colony of $C$. capsici. A similar study by Begum and Nath (2015) indicated that $T$. harzianum isolate Th-2 was effective on inhibiting the mycelia growth of all isolates of $C$. capsici where the highest percent that been observed was $100 \%$ inhibition. However, in the present study, the inhibition of mycelial growth of $C$. capsici by the Trichoderma sp. was only $30.87 \%$.

Previous study reported inhibitory mechanisms by Trichoderma virens and Trichoderma harzianum to $C$. truncatum through competition, parasitism and antibiosis (Begum et al., 2008). However, in this study, coiling and penetration of Trichoderma sp. were not observed in the SEM analysis. The Trichoderma sp. grew over the colony of $C$. capsici and at the point where the two fungi encountered, mycelia of $C$. capsici was found to 
change in turgidity. This change in shape might be attributed to the ability of Trichoderma sp. to secrete enzymes such as chitinase and glucanase which were reported in the study by Alka et al. (2017). According to Cuervo-Parra et al. (2011), deformation and disorganization of cell wall structure of Moniliophthora rorer which became rough was due to antifungal substances secretion of Trichoderma such as enzymes and antibiotics. In addition, the change in the shape of hyphae of $C$. capsici by Trichoderma sp. which became rough in structure in this study might also be due to lysis (Shahbazi et al., 2014). A study conducted by Palaniyandi et al. (2013) also recorded the occurrence of lysis on the fungal mycelia of $C$. coccodes by Streptomyces phaeopurpureus.

In this study, reduced growth of $C$. capsici in the volatile metabolite experiment illustrated the ability of the Trichoderma sp. to produce volatile metabolites. This mechanism has been reported for the $T$. virens and T. harzianum by Amin et al. (2010b) to control the mycelial growth of $C$. capsici by more than $50 \%$ and the radial growth was $12.73 \mathrm{~mm}$ and $13.41 \mathrm{~mm}$ respectively. Waterhouse (1968) also reported that metabolites produced by Trichoderma sp. was effective against $C$. gloeosporioides. Besides, Trichoderma sp. produced volatile metabolites which suppressed the growth of Pythium aphanidermatum (Muthukumar et al., 2011). Well known volatiles produced by Trichoderma spp. are trichodermin and trichodermol which are able to degrade cell wall of pathogens (Elad, 2000).

In vivo study was implemented to examine or verify whether the isolated Trichoderma would be effective in natural condition. In the presence of Trichoderma sp., disease severity caused by $C$. capsici was reduced in the present study. Similarly, in the study by Vasanthakumari and Shivanna (2014), T. harzianum decreased incidence and severity of the disease caused by $C$. graminicola in sorghum. The growth of the Trichoderma sp. on the surface of the wounded chilli fruits in this study might be due to the ability of Trichoderma sp. to colonize on the fruit surface (Ippolito \& Nigro, 2000) and niche overlap between competitors is required to perform successful colonization (Kinkel \& Lindow, 1997). However, the presence of the
Trichoderma mycelia on chilli fruits would affect the visual appearance of the fruits, which in turn would reduce its acceptability by consumers. Therefore, culture filtrate of Trichoderma sp. was used in a subsequent in vivo experiment.

Significant suppression in the growth of $C$. capsici and the development of anthracnose disease on the artificially inoculated chilli fruits by the culture filtrates of Trichoderma sp. suggested that the isolated Trichoderma sp. produced substances which might have antifungal effect. Shi et al. (2012) reported the production of antimicrobial peptides by $T$. pseudokoningii again a number of plant fungal pathogens while Vinale et al. (2014) discussed various secondary metabolites produced by Trichoderma genus, which are toxic to phytopathogens. Trichoderma spp. were also reported to produce many cell wall degrading enzyme such as xylanase and chitinase (Pandey et al., 2015). The finding in the present study agree with the study conducted by Rahman et al. (2012) who also found that application of culture filtrate of $T$. harzianum significantly decreased the disease severity caused by $C$. capsici. In addition, Rahman et al. (2013) reported that 30 day old culture filtrates of all Trichoderma strains in their study significantly reduced percentage of anthracnose disease severity on chilli fruits. According to Padder and Sharma (2011), Trichoderma viride has the best potential to inhibit mycelia growth and germination of spore of Colletotrichum lindemuthianum. Finally, higher percent inhibition (64\%) of Trichoderma sp. toward $C$. capsici when Trichoderma plugs were used compared to 55\% inhibition when culture filtrate was applied in this study indicated that, apart from antifungal effects, competition for space and nutrients could be another antagonism mechanism employed by Trichoderma sp. to inhibit the growth of $C$. capsici and the anthracnose development on the artificially infected fruits.

\section{CONCLUSION}

The isolated Trichoderma sp. has the potential as a biological control agent for Colletotrichum capsici, the pathogen of chilli anthracnose. It inhibited the growth of the pathogen on culture and reduced the disease severity on the chilli 
fruits. For post-harvest treatment, application of a culture filtrate of the Trichoderma sp. would be more appropriate to avoid the growth of the antagonist on the fruit surface, which will reduce the product appearance, thus market quality of the chilli fruits. However, in the field, the antagonist might be used in either form, with and without mycelia. In this study, the antagonistic ability of the isolated Trichoderma sp. was only tested in the laboratory or a controlled environment, so it would be worthwhile to examine the effect of the isolated Trichoderma sp. in the field conditions.

\section{ACKNOWLEDGEMENTS}

The authors thank the Faculty of Resource Science and Technology, Universiti Malaysia Sarawak for providing facilities, which enabled the completion of this study.

\section{REFERENCES}

Alka, Patil, R.K. \& Prajapati, B.K. (2017). Effect of Trichoderma spp. and its culture filtrate antagonists on growth and management of Rhizopus rot of tomato fruit in vitro and in vivo. Journal of Pharmacognosy and Phytochemistry, 6(4): 394-398.

Amin, F., Razdan, V.K., Mohiddin, F.A., Bhat, K. A. \& Saba, B. (2010a). Potential of Trichoderma species as biocontrol agents of soil borne fungal propagules. Journal of Phytology, 2(10): 38-41.

Amin, F., Razdan, V.K., Mohiddin, F.A., Bhat, K.A. \& Sheikh, P.A. (2010b). Effect of volatile metabolites of Trichoderma species against seven fungal plant pathogens in-vitro. Journal of Phytology, 2(10): 34-37.

Armando, N.G., Marfetán, J.A. \& Folgarait, P. J. (2017). Trichoderma species associated with acromyrmex ant nests from Argentina and first report of Trichoderma lentiforme for the country. Darwiniana, 5(1): 72-82.

Begum, M.M., Sariah, M., Abidin, Z.M.A., Puteh, A.B. \& Rahman, M.A. (2008). Antagonistic potential of selected fungal and bacterial biocontrol agents against Colletotrichum truncatum of soybean seeds. Pertanika Journal of Tropical Agriculture Science, 31: 45-53.
Begum, S. \& Nath, P.S. (2015). Eco-friendly management of anthracnose of chilli caused by Colletotrichum capsici. Journal of Applied and Natural Science, 7(1): 119 - 123.

Benítez, T., Rincón, A.M., Limón, M.C. \& Codón, A.C. (2004). Biocontrol mechanisms of Trichoderma strains. International Microbiology, 7: 249-260.

Bharathi, R., Vivekananthan, R., Harish, S., Ramanathan, A. \& Samiyappan, R. (2004). Rhizobacteria-based bio-formulations for the management of fruit rot infection in chillies. Crop Protection, 23(9): 835-843.

Carvalho, D.D.C., Junior, M.L., Martins, I., Inglis, P.W. \& Mello, S.C. (2014). Biological control of Fusarium oxysporum f. sp. phaseoli by Trichoderma harzianum and its use for common bean seed treatment. Tropical Plant Pathology, 39(5): 384-391.

Chernin, L. \& Chet, I. (2002). Microbial enzymes in biocontrol of plant pathogens and pests, Marcel Dekker Incorporate, New York, N.Y., 171-225.

Choi, Y.W., Hyde, K.D., \& Ho, W.W H. (1999). Single spore isolation of fungi. Fungal Diversity, 3: 29-38.

Cuervo-Parra, J.A., Ramírez-Suero, M., Sánchez-López, V. \& Ramírez-Lepe, M. (2011). Antagonistic effect of Trichoderma harzianum VSL291 on phytopathogenic fungi isolated from cocoa (Theobroma cacao L.) fruits. African Journal of Biotechnology, 10(52): 10657-10663.

Elad, Y. (2000). Biological control of foliar pathogens by means of Trichoderma harzianum and potential modes of action. Crop Protection, 19: 709-714.

Hill, R.A., Ambrose, A., Sajali, N.A., Yatim, M., Valdez, R.B., Agbayani, F., Bungang, J., Minchin, R.F. \& Stewart, A. (2010). Bioprotection of Acacia mangium using Trichoderma in Malaysia. Microbial Products: Exploiting microbial diversity for sustainable plant production (eds Zydenbos SM \& Jackson TA). New Zealand Plant Protection Society Incorporated, 51-55.

Intana, W., Suwanno, T., Chamswarng, C., Chantrapromma, K. \& Ngamriabsakul, C. (2007). Increased efficacy for controlling 
anthracnose of chili using antifungal metabolites from mutant strains of Trichoderma harzianum. Thai Journal of Agricultural Science, 40(1-2): 65-72.

Ippolito, A. \& Nigro, F. (2000). Impact of preharvest application of biological control agents on postharvest diseases of fresh fruits and vegetables. Crop Protection, 19: 715723.

Karim, M.S.A., Rashid, S.S.A., Adzahan, N.M. \& Camillo, A. A. (2011). Consumers' Perspective Towards Malaysian Traditional Food: Sambal Belacan (Chilli Shrimp Paste), A Preliminary Investigation. Journal of Agribusiness Marketing, 4: 68-92.

Kim, H.J., Lee, E.J., Park, S.H., Lee, H.S. \& Chung, N. (2014). Biological control of anthracnose (Colletotrichum gloeosporioides) in pepper and cherry tomato by Streptomyces sp. A1022. Journal of Agricultural Science, 6(2): 54.

Kinkel, L.L. \& Lindow, S.E. (1997). Microbial competition and plant disease biocontrol. In: Andow, D. A., Ragsdale, D. W., Nyvall, R. F. (Eds.), Ecological Interaction and Biological Control. Westview Press, Boulder, CO, USA, 128-138.

Liu, F., Tang, G., Zheng, X., Li, Y., Sun, X., Qi, X., Zhou, Y., Xu, J., Chen, H., Chang, X. \& Zhang, S. (2016). Molecular and phenotypic characterization of Colletotrichum species associated with anthracnose disease in peppers from Sichuan Province, China. Scientific Reports, 6: 32761.

Montri, P., Taylor, P.W.J. \& Mongkolporn, O. (2009). Pathotypes of Colletotrichum capsici, the causal agent of chili anthracnose, in Thailand. Plant Disease, 93: 17-20.

Muthukumar, A., Eswaran, A. \& Sanjeevkumas, K. (2011). Exploitation of Trichoderma species on the growth of Pythium aphanidermatum in chilli. Brazilian Journal of Microbiology, 42: 1598-1607.

Naipagropediaraichur. (2012). Chilli Anthracnose. Retrieved August 24, 2017 from http://agropedia.iitk.ac.in/content/chilli -anthracnose
Nantawanit, N., Chanchaichaovivat, A., Panijpan, B. \& Ruenwongsa, P. (2010). Induction of defense response against Colletotrichum capsici in chili fruit by the yeast Pichi guilliermondii strain R13. Biological Control, 52: 145-152.

Ngullie, M., Daiho, L. \& Upadhyay, D.N. (2010). Biological management of fruit rot in the world's hottest chilli (Capsicum chinense Jacq.). Journal of Plant Protection Research, 50(3): 269-273.

Padder, B.A. \& Sharma, P.N. (2011). In vitro and in vivo antagonism of biocontrol agents against Colletotrichum lindemuthianum causing bean anthracnose. Archives of Phytopathology and Plant Proctection, 44(10): 961-969.

Palaniyandi, S.A., Yang, S.H. \& Suh, J.W. (2013). Extracellular proteases from Streptomyces phaeopurpureus ExPro138 inhibit spore adhesion, germination and appressorium formation in Colletotrichum coccodes. Journal of Applied Microbiology, 115: 207-217.

Pandey K.K. \& Pandey P.K. (2003). Survey and surveillance of vegetable growing areas for prevalence of major diseases. Journal of Vegetation Science, 30(20): 128-134.

Pandey, S., Srivastava, M., Shahid, M., Kumar, V., Singh, A., Trivedi, S. \& Srivastava, Y.K. (2015). Trichoderma species cellulases produced by solid state fermentation. Journal of Data Mining in Genomics \& Proteomics, 6(2): 170.

Rahman, AM., Rahman, M. M., Azad, K.A. \& Alam, F.M. (2011). Inhibitory effect of different plant extracts and antifungal metabolites of Trichoderma strains on the conidial germination and germ tube growth of Colletotrichum capsici causing chili anthracnose. International Journal of Agronomy and Agricultural Research, 1(1): 20-28.

Rahman, M.A., Rahman, M.M., Kamruzzaman, M., Begum, M.F. \& Alam, M.F. (2012). Use of culture filtrates of Trichoderma strains as a biological control agent against Colletotrichum capsic $i$ causing anthracnose fruit rot disease of chili. Journal of Biodiversity and Environmental Sciences, 2(1): 9-18. 
Rahman, M.A., Razvy, M.A. \& Alam, M.F. (2013). Antagonistic activities of Trichoderma strains against chili anthracnose pathogen. International Journal of Microbiology and Mycology, 1(1): 7-22.

Ratanacherdchai, K., Wang, H.K., Lin, F.C. \& Soytong, K. (2010). ISSR for comparison of cross-inoculation potential of Colletotrichum capsici causing chilli anthracnose. African Journal of Microbiology Research, 4(1): 7683.

Rosli, N.A. (2017). Antimicrobial properties of Manihot esculenta, Cymbopogon citratus and Mentha piperita against crop pathogens. (Doctoral dissertation, UNIMAS).

Sangdee, A., Sachan, S. \& Khankhum, S. (2011). Morphological, pathological and molecular variability of Colletotrichum capsici causing anthracnose of chilli in the North-east of Thailand. African Journal of Microbiology Research, 5(25): 4368-4372.

Sawant, I.S. (2014). Trichoderma- foliar pathogen interactions. The Open Mycology Journal, 8: 58-70.

Saxena, A., Raghuwanshi, R., Gupta, V.K. \& Singh, H. B. (2016). Chilli Anthracnose: The Epidemiology and Management. Frontiers in Microbiology, 7: 1527.

Shah, S., Nasreen, S. \& Sheikh, P.A. (2012). Cultural and morphological characterization of Trichoderma spp. associated with green mold disease of Pleurotus spp. in Kashmir. Research Journal of Microbiology, 7(2): 139-144.

Shahbazi, P., Musa, M.Y., Tan, G.Y.A., Avin, F. A., Teo, W.F.A. \& Sabaratnam, V. (2014). In vitro and in vivo evaluation of Streptomyces suppressions against anthracnose in chili caused by Colletotrichum. Sains Malaysiana, 43(5): 697-705.

Shenoy, B.D., Jeewon, R., Lam, W.H., Bhat, D. J., Than, P.P., Taylor, P.W.J. \& Hyde, K.D. (2007). Morpho-molecular characterization and epitypification of Colletotrichum capsici (Glomerellaceae, Sordariomycetes), the causative agent of anthracnose in chilli. Fungal Diversity, 27: 197-211.

Shi, M., Chen, L., Wang, X. W., Zhang, T., Zhao, P.B., Song, X.Y., Sun, C.Y., Chen, X.L., Zhou, B.C. \& Zhang, Y.Z. (2012). Antimicrobial peptaibols from Trichoderma pseudokoningii induce programmed cell death in plant fungal pathogens. Microbiology, 158: 167-175.

Than, P.P., Prihastuti, H., Phoulivong, S., Taylor, P.W. \& Hyde, K.D. (2008a). Chilli anthracnose disease caused by Colletotrichum species. Journal of Zhejiang University Science B, 9(10): 764-778.

Than, P.P., Jeewon, R., Hyde, K.D., Pongsupasamit, S., Mongkolporn, O. \& Taylor, P.W.J. (2008b). Characterization and pathogenicity of Colletotrichum species associated with anthracnose disease on chilli (Capsicum spp.) in Thailand. Plant Pathology, 57(3): 562-572.

Vasanthakumari, M.M. \& Shivanna, M.B. (2014). Biological control of sorghum anthracnose with rhizosphere and rhizoplane fungal isolates from perennial grasses of the Western Ghats of India. European Journal of Plant Pathology, 139: 721-733.

Verma, M., Brar, S.K., Tyagi, R.D., Surampalli, R.Y. \& Valero, J.R. (2007). Antagonistic fungi, Trichoderma spp.: Panoply of biological control. Biochemical Engineering Journal, 37(1): 1-20.

Vinale, F., Sivasithamparam, K., Ghisalberti, E. L., Woo1, S. L., Nigro, M., Marra, R., Lombardi, N., Pascale, A., Ruocco, M., Lanzuise, S., Manganiello, G. \& Lorito, M. (2014). Trichoderma secondary metabolites active on plants and fungal pathogens. The Open Mycology Journal, 8, (Suppl-1, M5): 127-139.

Waterhouse, G.M. (1968). The genus Pythium Pringsheim. Mycological Papers, 110: 1-50.

Williams, C.N., Uzo, J.O. \& Peregrine, W.T.H. (1991). Vegetable Production in the Tropics. England: Longman Scientific \& Technical. P 179. 